\title{
Synthesis of a Large Organometallic Macrocycle Comprising Four Ga-Ga Bonds and Four Bridging Ferrocene Dicarboxylato Ligands ${ }^{\dagger}$
}

\author{
Werner Uhl* and Thomas Spies \\ Fachbereich Chemie der Philipps Universität Marburg, Hans-Meerwein-Strasse, \\ D-35032 Marburg, Germany \\ Detlev Haase \\ Fachbereich Chemie, Carl-von-Ossi etzky U niversität, Postfach 2503, \\ D-26111 Oldenburg, Germany \\ Rainer Winter and Wolfgang Kaim \\ Institut für Anorganische Chemie, Universität Stuttgart, Pfaffenwaldring 55, \\ D-70550 Stuttgart, Germany
}

Received November 1, 1999

\begin{abstract}
The reaction of tetrakis[bis(trimethylsilyl)methyl]digallane(4), $\mathbf{1}$, with $1,1^{\prime}$-ferrocenedicarboxylic acid afforded orange-red crystals of the macrocyclic compound $\mathbf{2}$ in a yield of $84 \%$. 2 contains a large 32-atom heterocycle, which comprises four $\mathrm{Ga}-\mathrm{Ga}$ single bonds bridged by four $1,1^{\prime}$-ferrocenedicarboxylato ligands. The largest diameter of the molecule is about $2.5 \mathrm{~nm}$. The redox-active Ga-Ga sites and ferrocene iron centers are all oxidized irreversibly within a narrow potential range.
\end{abstract}

\section{Introduction}

Recently, we isolated the first organoelement compounds containing $\mathrm{Al}-\mathrm{Al},{ }^{1} \mathrm{Ga}-\mathrm{Ga}(\mathbf{1}),{ }^{2}$ or $\mathrm{In}-\mathrm{In}^{3}$ single bonds which were sterically shiel ded and stabilized by four bulky bis(trimethylsilyl)methyl substituents. They showed an unprecedented chemical reactivity, and up to now we observed six different types of reaction, ${ }^{4}$ of which the substituent exchange with retention of the element-element bonds is of particular interest. Such reactions succeeded only by treating the digallium compound $\mathbf{1}$ with protonic acids, ${ }^{5-8}$ while the cleavage of the AI-AI or $\mathrm{In}-\mathrm{In}$ bonds and complete oxidation of the Al or In atoms were observed under similar conditions for the dialuminum and diindium analogues. ${ }^{8,9}$ Carboxylic acids reacted with $\mathbf{1}$ by the release of 2 equiv of $\mathrm{CH}_{2}\left(\mathrm{SiMe}_{3}\right)_{2}$ and the almost quantitative formation of products in which the intact $\mathrm{Ga}-\mathrm{Ga}$ bonds were bridged by two carboxylato ligands..$^{5-7}$ In contrast, a terminal coordination was observed for acetylacetonato derivatives ${ }^{8}$ or the diphenyltriazenido ligand. ${ }^{10,11} \mathrm{Di}$ -

† Dedicated to Prof. Gerd Becker on the occasion of his 60th birthday.

(1) Uhl, W. Z. Naturforsch., B: Chem. Sci. 1988, 43, 1113.

(2) Uhl, W.; Layh, M.; Hildenbrand, T. J . Organomet. Chem. 1989, 364, 289.

(3) Uhl, W.; Layh, M.; Hiller, W. J . Organomet. Chem. 1989, 368, 139

(4) Uhl, W. Coord. Chem. Rev. 1997, 163, 1.

(5) Uhl, W.; Hahn, I.; Reuter, H. Chem. Ber. 1996, 129, 1425.

(6) Uhl, W.; Spies, T.; Koch, R. J . Chem. Soc., Dalton Trans. 1999, 2385.

(7) Uhl, W.; Spies, T.; Saak, W. Eur. J . Inorg. Chem. 1998, 1661.

(8) Uhl, W.; Graupner, R.; Hahn, I.; Spies, T.; Frank, W. Eur. J .

Inorg. Chem. 1998, 355

(9) Uhl, W.; Graupner, R.; Pohl, S.; Saak, W.; Hiller, W.; Neumayer, M. Z. Anorg. Allg. Chem. 1997, 623, 883. carboxylato acids such as 1,4-benzenedi (methylcarboxylic) acid or 1,4-cycl ohexanedicarboxylic acid gave macrocyclic compounds with up to 22 atoms, ${ }^{7}$ in which two dialkyldigallium moieties were bridged by two dicarboxylato ligands. These reactions opened a very effective and simple route for the synthesis of such macrocyclic compounds and afforded the products in yields of more than $80 \%$ under quite normal conditions and with no consideration of the dilution principle. The dicarboxylic acids employed so far contained rather flexible hydrocarbon backbones, and we were much interested in employing more rigid systems, to obtain larger macrocycles or even polymers. The results obtained with $1,1^{\prime}$ ferrocenedicarboxylic acid are reported here.

\section{Results and Discussion}

A stoichiometric $1: 1$ mixture of compound 1 and 1, $1^{\prime}$ ferrocenedicarboxylic acid was dissolved in n-hexane and stirred at room temperature for $24 \mathrm{~h}$. An orangered solution was obtained, from which orange-red crystals of the macrocyclic product $\mathbf{2}$ were isolated in a yield of $84 \%$ after evaporation and recrystallization of the residue from cyclopentane (eq 1). Solid samples of $\mathbf{2}$ are air-stable for several days and decompose only above $280{ }^{\circ} \mathrm{C}$. The ${ }^{1} \mathrm{H}$ and ${ }^{13} \mathrm{C}$ NMR signals of the methine groups attached to gallium are shifted to high field $\left({ }^{1} \mathrm{H}, \delta=-0.32 ;{ }^{13} \mathrm{C}, \delta=4.5\right)$ in comparison with

(10) Uhl, W.; Hahn, I.; Wartchow, R. Chem. Ber./ Red. 1997, 130, 417.

(11) F urther examples for bridging versus terminal coordination of the Ga-Ga bond: Uhl, W.; Spies, T.; Saak, W. Z. Anorg. Allg. Chem. 1999, 625, 2095. 


$$
\underset{\left(\mathrm{Me}_{3} \mathrm{Si}\right)_{2} \mathrm{HC}}{\left(\mathrm{Me}_{3} \mathrm{Si}\right)_{2} \mathrm{HC}} \overbrace{\mathrm{CH}\left(\mathrm{SiMe}_{3}\right)_{2}}^{\mathrm{CH}\left(\mathrm{SiMe}_{3}\right)_{2}}+2 \mathrm{Fe}\left(\mathrm{C}_{5} \mathrm{H}_{4} \mathrm{COOH}\right)_{2} \underset{-2 \mathrm{CH}_{2}\left(\mathrm{SiMe}_{3}\right)_{2}}{\longrightarrow}
$$

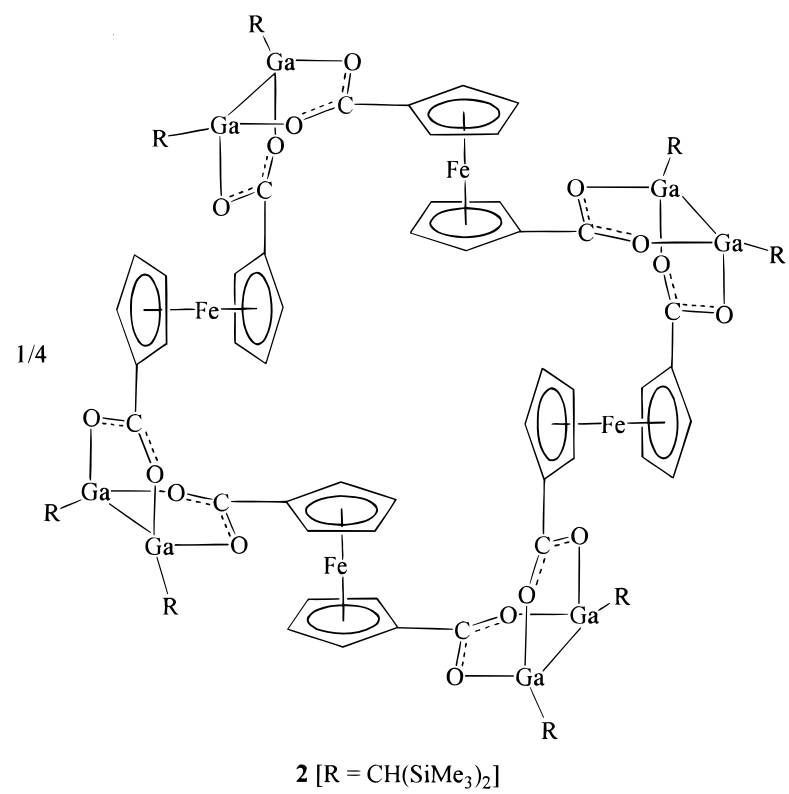

the starting compound $\mathbf{1}^{2}\left({ }^{1} \mathrm{H}, \delta=1.11 ;{ }^{13} \mathrm{C}, \delta=25.9\right)$, which is very indicative of an enhancement of the coordination number of the gallium atoms from three to four. 5,8,12 The intensity ratios of the proton resonances showed that two bis(trimethylsilyl)methyl groups were replaced by a ferrocene dicarboxylato ligand. An absorption at $1532 \mathrm{~cm}^{-1}$ was observed for the $\mathrm{CO}_{2}$ stretching vibration in the IR spectrum, which is identical to values obtained for the other dicarboxylatodigallium species cited above. ${ }^{5-7}$ An impurity of about $10 \%$ was detected in all NMR spectra at room temperature $\left({ }^{1} \mathrm{H} N M R\right.$, $\mathrm{SiMe}_{3}, \delta=0.39$; $\left.\mathrm{GaCH}, \delta=-0.20\right)$; its intensity remained unchanged even after repeated recrystallization. However, its concentration changed reversibly with temperature and increased to $30 \%$ upon heating to 80 ${ }^{\circ} \mathrm{C}$. Thus, we suppose that compound $\mathbf{2}$ partially dissociates in solution to give molecules containing three or two digallium units. Owing to the low solubility of $\mathbf{2}$ in benzene, we unfortunately did not succeed in determining the molar mass of $\mathbf{2}$, so that we have no information concerning the size of the molecules in solution at all. The "dimeric" formula unit with two $\mathrm{Ga}-\mathrm{Ga}$ bonds and two ferrocene dicarboxylato bridges was detected as the highest mass in the mass spectrum.

Compound $\mathbf{2}$ crystallizes with three molecules in the unit cell, of which one is located on a crystallographic center of symmetry. The structure of one molecule is depicted in Figure 1. 2 has a large macrocycle in its molecular center comprising four dialkyldigallium groups bridged by four ferrocene dicarboxylato ligands, which give a total number of 32 atoms in the heterocycle. The $\mathrm{Ga}-\mathrm{Ga}$ bonds are bridged by two carboxylato ligands in a chelating manner and have short lengths of 2.382

(12) (a) Uhl, W.; Hahn, I.; Koch, M.; Layh, M. Inorg. Chim. Acta 1996, 249, 33. (b) Uhl, W.; Gerding, R.; Hannemann, F. Z. Anorg. Allg. Chem. 1998, 624, 937.

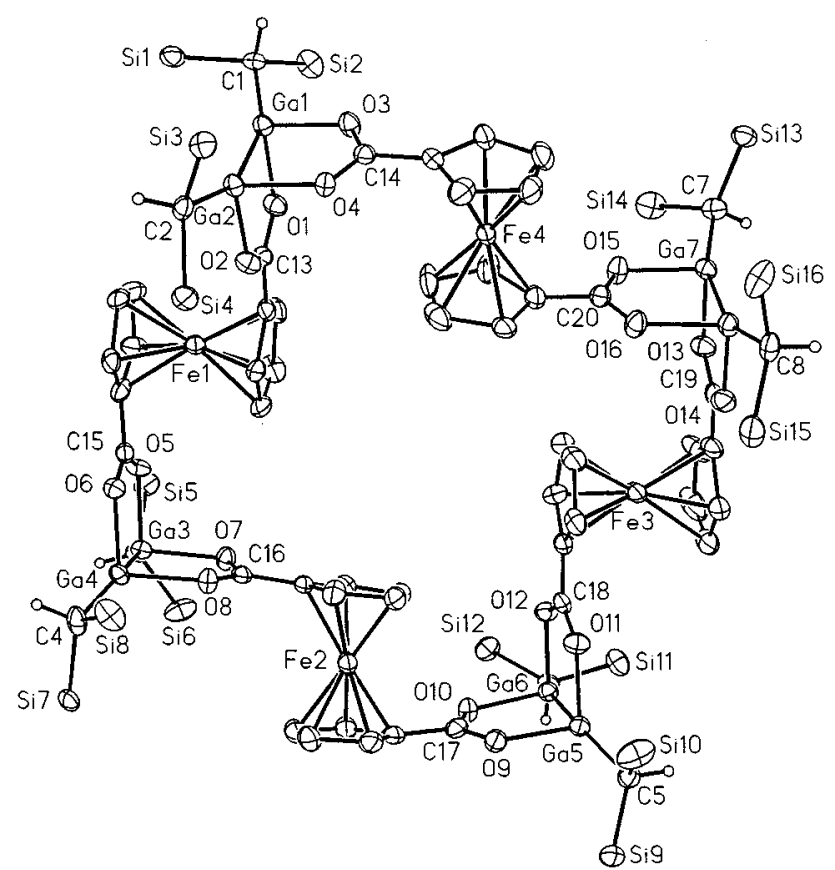

Figure 1. Molecular structure of one of the independent molecules of $\mathbf{2}$. The thermal ellipsoids are drawn at the $40 \%$ probability level. Methyl groups are omitted for clarity. Important bond lengths $(\AA)$ and angles (deg): Ga-Ga 2.3700(9)-2.3984(9) (av 2.3821), Ga-O 1.994(4)-2.042(4) (av 2.010), Ga-Ga-C 153.5(2)-158.8(2) (av 156.8), O-Ga-O 91.5(2)-95.1(2) (av 93.5), Ga-Ga-O 87.2(1)89.5(1) (av 88.1).

$\AA$ on average (1: $2.541 \AA)^{2}$ The carboxylato groups coordinated to one $\mathrm{Ga}-\mathrm{Ga}$ bond are almost perpendicular to one another, and the $\mathrm{Ga}-\mathrm{O}$ bonds enclose angles of $93.5^{\circ}$. The $\mathrm{Ga}-\mathrm{Ga}-\mathrm{C}$ bond angl es approach linearity (156.8 $8^{\circ}$ on average). A particular bonding situation results that may be interpreted in terms of sp-hybridized gallium atoms and was discussed in detail elsewhere. ${ }^{6}$ The $\mathrm{CO}_{2}$ groups of each ferrocene unit occupy trans positions. The cyclopentadienyl rings and their attached $\mathrm{Ga}_{2} \mathrm{O}_{2} \mathrm{C}$ heterocycles are al most ideally coplanar, and the normals of the planes enclose angles between $2.8^{\circ}$ and $16.3^{\circ}$. The $\mathrm{Fe}-\mathrm{C}$ distances are similar to those often observed before.

The $\mathrm{Ga}-\mathrm{Ga}$ bonds are perpendicular to the molecular plane. But the ferrocene groups adopt orientations in which one cyclopentadienyl ring points toward the center of the heterocycle ("in"), while the second one is on its surface ("out"). Such an arrangement causes a chiral environment of the gallium atoms, because each $\mathrm{Ga}-\mathrm{Ga}$ bond is coordinated by two chemically different carboxylato ligands, of which one is attached to an "in" and one to an "out" Cp ring. Owing to this particular coordination, the trimethylsilyl groups of each bis(trimethylsilyl)methyl substituent should become diastereotopic. However, at room temperature only singlets were observed in the ${ }^{1} \mathrm{H}$ and ${ }^{13} \mathrm{C}$ NMR spectra, and a splitting into two resonances of equal intensity was detected only upon cooling of a solution of $\mathbf{2}$ in toluene to $-40{ }^{\circ} \mathrm{C}$. As expected, the methine protons occurred as a single resonance at all temperatures. The cyclopentadienyl hydrogen atoms gave four resonances of equal intensity at low temperature, while only two resonances were observed upon heating to $80^{\circ} \mathrm{C}$. Thus, the molecule shows a dynamic behavior in solution at 
elevated temperature, which results in the rapid exchange between the "in" and "out" positions of the ferrocene ligands. This process is frozen at low temperature, and NMR spectra were obtained that are consistent with those predicted from the solid-state structure. The energy barrier $\Delta \mathrm{G}^{\ddagger}$ of this exchange process was estimated ${ }^{13}$ to be $\approx 60 \mathrm{~kJ} / \mathrm{mol}$.

Compound $\mathbf{2}$ provides a very nice example of a large macrocyclic molecule in the nanometer scale obtained by a facile and very effective route. The largest di ameter found between peripheral hydrogen atoms is about 2.5 $\mathrm{nm}$. The separation between carbon atoms of the " $\mathrm{n}$ " cyclopentadienyl rings is between 7.60 and $8.40 \AA$, and the intramolecular Fe-Fe distances are about $7.80 \AA$ between neighboring and $11.00 \AA$ between opposite iron atoms. Owing to the particular conformation of the molecule, its cavity is not very large, and both diisopropyl ether molecules enclosed in the crystals per formula unit are not encapsulated, as observed several times before, ${ }^{14,15}$ but situated in hollows above and below the heterocycles.

The electrochemical behavior of the ferrocene-digallium tetramer was investigated in both dichloromethane and THF solvents at room temperature and at $-40{ }^{\circ} \mathrm{C}$ (THF) and $-78{ }^{\circ} \mathrm{C}\left(\mathrm{CH}_{2} \mathrm{Cl}_{2}\right)$. The qual itative behavior is similar in both cases, showing three distinct anodic features with the better resolution in THF. In this solvent a first irreversible process occurs at a peak potential of $0.365 \mathrm{~V}(0.2 \mathrm{~V} / \mathrm{s})$ versus the internal ferrocene standard. Under no conditions did we observe a directly associated cathodic peak. An irreversible cathodic feature at a peak potential of $-1.76 \mathrm{~V}$ is found instead, which is absent if the cathodic regime is scanned first. This points to a fast chemical reaction following oxidation, producing a new electroactive species, which then is reduced at the much more cathodic potential. The first irreversible process is fol lowed by a largely reversible wave at a half-wave potential of 0.41 $\mathrm{V}$. At still higher potential another irreversible feature with a peak potential of $0.58 \mathrm{~V}(0.2 \mathrm{~V} / \mathrm{s})$ is observed. Scanning this process causes a significant increase in peak current of the cathodic return peak that had al ready been observed as arising from the chemical decomposition following the first oxidation. Due to the sluggish electron transfer of at least the second anodic step, the latter two waves merge at lower temperatures to an ill-defined composite feature. In $\mathrm{CH}_{2} \mathrm{Cl}_{2}$ the overall behavior is additionally complicated by the lower chemical reversi bility of the second couple. In this solvent the associated cathodic reverse peak is obtained at fast sweep rates or low temperatures only, i.e., under conditons where no resolution of the second and third anodic process is attained. We al so addressed the question of how many electrons are transferred in the overall oxidation process by comparing the diffusion-controlled current from a large potential step in chronoamperometry and the limiting current from steady-state voltammetry with those of the ferrocene standard, as suggested by Baranski et al. ${ }^{16}$ The result proved to be solvent dependent with $\mathrm{n}=8.7$ in THF and 12 in $\mathrm{CH}_{2} \mathrm{Cl}_{2}$.

(13) Günther, H. NMR-Spektroskopie; Thieme Verlag: Stuttgart, 1983.

(14) Rettig, S. J .; Storr, A.; Trotter, J . Can. J . Chem. 1999, 77, 434

(15) Lehn, J.-M. Supramol ecular Chemistry; VCH: Weinheim, 1995.
Each ferrocenodicarboxylatodigallium(II) unit of the tetramer offers two possible oxidation sites: the ferrocene iron and the Ga-Ga bond, which may be oxidized by two electrons in one or two consecutive steps. The irreversibility of both the first and third oxidation step and the identical electroactive product arising from the chemical decomposition following these oxidations let us assume that these two features are associated with stepwise oxidation of the $\mathrm{Ga}-\mathrm{Ga}$ bond. The second oxidation feature is then attributed to the iron(II) center of the ferrocene dicarboxylate subunits, in line with the at least partially reversible nature of this process. In the tetramer four of these subunits are combined in a wheel-like structure, giving a total number of 12 electrons per molecule in accord with our experimental findings. Since only three waves are observed for the whole molecule, we may conclude that the individual electroactive subunits within the tetramer are electrochemically isolated against each other. Taking into account the long $\mathrm{Fe}-\mathrm{Fe}$ distance of $7.8 \AA$, the similar separation between the digallium centers, and the insulating nature of the bridges between identical redox centers, this assumption appears to be well justified.

The facile synthesis of those macrocycles by treatment of the digallium compound $\mathbf{1}$ with dicarboxylic acids verifies that the $\mathrm{Ga}-\mathrm{Ga}$ bond is a very efficient building block for selective molecular self-assembly processes. ${ }^{15}$ We hope to further use this method for the synthesis of a broad variety of macrocyclic compounds and to investigate the physical and chemical properties of those macromolecules systematically, for instance with respect to their application as chelating ligands in molecular recognition.

\section{Experimental Section}

All procedures were carried out under purified argon. n-H exane and cyclopentane were dried over $\mathrm{LiAlH}_{4}$; diisopropyl ether, over $\mathrm{Na}$ /benzophenone. Commercially available 1,1'ferrocenedicarboxylic acid (Aldrich) was employed without further purification. Compound $\mathbf{1}$ was synthesized as described in ref 2.

Synthesis of Compound 2. Compound $1(0.220 \mathrm{~g}, 0.284$ $\mathrm{mmol}$ ) was dissolved in $25 \mathrm{~mL}$ of $\mathrm{n}$-hexane, cooled to $-50{ }^{\circ} \mathrm{C}$, and treated with solid $1,1^{\prime}$-ferrocenedicarboxylic acid $(0.078$ $\mathrm{g}, 0.285 \mathrm{mmol}$ ) in small portions. The solution was allowed to warm to room temperature and stirred for $24 \mathrm{~h}$. The solvent was removed in vacuo, and the residue was dissolved in 10 $\mathrm{mL}$ of cycl opentane or diisopropyl ether. Orange-red crystals of $\mathbf{2}$ were isolated after filtration, concentration, and cooling of the solution to $-30{ }^{\circ} \mathrm{C}$. Yield: $0.175 \mathrm{~g}$ (84\%). Dec (argon, sealed capillary): $280{ }^{\circ} \mathrm{C}$. Anal. Calcd for $\mathrm{C}_{104} \mathrm{H}_{184} \mathrm{O}_{16} \mathrm{Si}_{16} \mathrm{Fe}_{4}$ $\mathrm{Ga}_{8}$ (2921.13): Ga, 19.1; Fe, 7.6. F ound: $\mathrm{Ga}, 19.1 ; \mathrm{Fe}, 7.8 .{ }^{1} \mathrm{H}$ NMR (toluene- $d_{8}, 300 \mathrm{MHz}, 353 \mathrm{~K}$ ): $\delta=4.90$ and 4.17 (each $16 \mathrm{H}, \mathrm{s}, \mathrm{br}, \mathrm{Cp}), 3.46$ ( $2 \mathrm{H}$, septett, $\mathrm{OCH}$ of di isopropyl ether), $1.03(12 \mathrm{H}, \mathrm{d}$, Me of diisopropyl ether), 0.34 (144 H, s, SiMes), $-0.32(8 \mathrm{H}, \mathrm{s}, \mathrm{GaCH}) .{ }^{1} \mathrm{H}$ NMR (toluene- $\mathrm{d}_{8}, 300 \mathrm{MHz}, 233 \mathrm{~K}$ ): $\delta=5.07,4.90,4.46$ and 3.86 (each $8 \mathrm{H}, \mathrm{s}, \mathrm{br}, \mathrm{Cp}), 3.41(2 \mathrm{H}$, septett, $\mathrm{OCH}$ of diisopropyl ether), $1.09(12 \mathrm{H}, \mathrm{d}, \mathrm{Me}$ of diisopropyl ether), 0.46 and 0.37 (each $72 \mathrm{H}, \mathrm{s}, \mathrm{SiMe3}$ ), -0.45 $(8 \mathrm{H}, \mathrm{s}, \mathrm{GaCH}) .{ }^{13} \mathrm{C} N M R\left(\mathrm{C}_{6} \mathrm{D}_{6}, 75.5 \mathrm{MHz}\right): \delta=182.9\left(\mathrm{CO}_{2}\right)$ 75.0 and 72.5 (br, Cp), $4.2(\mathrm{GaC}), 3.5\left(\mathrm{SiMe}_{3}\right)$. IR (CsBr plates, paraffin, $\mathrm{Cm}^{-1}$ ): $1532 \mathrm{~m} v \mathrm{CO}_{2} ; 1464$ vs, 1377 vs paraffin; 1366 s Cp; 1304 vw, 1256 sh, $1246 \mathrm{~m} \mathrm{\delta CH}$; $1192 \mathrm{~m}, 1169$ vw, 1153 vw, 1113 w, 1080 w, 1051 m, 1028 m vCC; 1013 s $\delta C H ; 951$

(16) Baranski, A. S.; Fawcett, W. R.; Gilbert, C. M. Anal. Chem. 1985, 57, 7, 166. 
m, 918 w, 862 s, 843 vs, 805 w, 791 m, 777 m, 760 m, 721 m

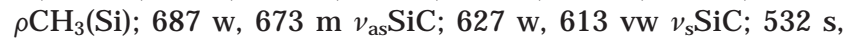
$465 \mathrm{w} v \mathrm{GaC}, v \mathrm{GaO} ; 347 \mathrm{vw}, 324 \mathrm{vw} \delta \mathrm{SiC}$. UV/vis (n-hexane): $\lambda_{\max }(\log \epsilon): 207$ (4.8), 214 (4.8), 226 (4.9), 232 (4.8), 261 (4.7), 323 (4.0), 457 (3.1). MS: m/z (\%) (EI) 1454.7 (30\% rel int.), $1455.5(55 \%), 1456.7$ (95\%), $1457.6(98 \%), 1458.6(100 \%)$, $1459.6(65 \%), 1460.5(60 \%)$ all $\mathrm{M}^{+}$of the dimeric ferrocenedicarboxylatodigallium compound in accordance with a calculated isotope pattern.

Crystal Structure Determination. Single crystals of $\mathbf{2}$. $2 \mathrm{iPr}_{2} \mathrm{O}$ were obtained by cooling of a saturated solution in diisopropyl ether to $-15^{\circ} \mathrm{C}$. The crystals were not evacuated. The crystallographic data were collected with a STOE imaging plate diffractometer: $\mathrm{C}_{116} \mathrm{H}_{212} \mathrm{O}_{18} \mathrm{Si}_{16} \mathrm{Fe}_{4} \mathrm{Ga}_{8}$, triclinic, $\mathrm{P} \overline{\mathrm{l}}$; no. $2,{ }^{17} \mathrm{Z}=3$, temperature $193(2) \mathrm{K}, \mathrm{D}_{\text {calcd }}=1.315 \mathrm{~g} / \mathrm{cm}^{3} ; \mathrm{a}=$ 21.234(2) $\AA, b=25.902(3) \AA, c=26.060$ (3) $\AA, \alpha=73.26(1)^{\circ}, \beta$ $=66.05(1)^{\circ}, \gamma=66.10(1)^{\circ} ; \mathrm{V}=11844(2) \times 10^{-30} \mathrm{~m}^{3} ; \mu=1.869$ $\mathrm{mm}^{-1}$; crystal dimensions $1.24 \times 0.43 \times 0.40 \mathrm{~mm}$; radiation Mo K $\alpha$, graphite monochromator; $2 \theta$ range $4^{\circ} \leq 2 \theta \leq 52^{\circ}$; index ranges $-26 \leq \mathrm{h} \leq 26,-31 \leq \mathrm{k} \leq 32,-31 \leq \mathrm{I} \leq 32 ; 313$ exposures; $\Delta \varphi=0.8^{\circ}$; number of unique reflections 43329 ; number of parameters 2215. The structure was solved by direct methods and refined with the program SHELXL-9318 by a fullmatrix least-squares method based on $\mathrm{F}^{2}$. R1 (26352 reflections $\mathrm{I}>2 \sigma(\mathrm{I}))=0.0583$; $\mathrm{wR} 2$ (all data) $=0.1629 ; \mathrm{max} / \mathrm{min}$ residual electron density $=0.872 /-0.944 \times 10^{30} \mathrm{e} / \mathrm{m}^{3}$. Compound 2 crystallizes with 1.5 independent molecules in the asymmetric unit; one-half is generated by a crystallographic center of symmetry. Two molecules of diisopropyl ether enclose each formula unit of $\mathbf{2}$. Thus, three independent ether molecules were observed, one of which showed a disorder of its oxygen atom.

(17) Hahn, T., Ed. International Tables for Crystallography, Space Group Symmetry, Vol. A; Kluwer Academic Publishers: Dordrecht, 1989.

(18) SHELXTL-Plus, REL. 4.1; Siemens Analytical X-Ray Instruments Inc.: Madison, WI, 1990. Sheldrick, G. M. SHELXL-93, Program for the Refinement of Structures; Universität Göttingen, 1993.
Electrochemistry. All electrochemical experiments were performed in a home-built cylindrical vacuum-tight onecompartment cell. A spiral-shaped Pt wire and an Ag wire as the counter and reference electrodes are sealed directly into opposite sides of the glass wall, while the respective working electrodes (Pt, glassy carbon $1.1 \mathrm{~mm}, \mathrm{Au} 60 \mu \mathrm{m}$ diameter, polished with $0.25 \mu \mathrm{m}$ diamond paste (Buehler-Wirtz) before each series of experiments) are introduced via a Tefl on screw cap with a suitable fitting. The cell may be attached to a conventional Schlenk line via two sidearms equipped with Teflon screw valves and allows experiments to be performed under an atmosphere of argon with approximately $2.5 \mathrm{~mL}$ of analyte solution. The solvents were obtained in the highest available purity from commercial sources (Fluka; $\mathrm{CH}_{2} \mathrm{Cl}_{2}$ : Burdick\&J ackson Brand) and freshly distilled from $\mathrm{CaH}_{2}$ $\left(\mathrm{CH}_{2} \mathrm{Cl}_{2}\right)$ or $\mathrm{K}$ (THF) before the experiments. NBu $\mathrm{PF}_{6}(0.25$ $\mathrm{mM}$ ) was used as the supporting electrolyte. All potentials are referenced versus the internal ferrocene/ferrocinium couple. All electrochemical data were acquired with a computercontrolled EG\&G model 273 potentiostat utilizing the $E G \& G$ 250 software package.

Acknowledgment. We are grateful to the Deutsche Forschungsgemeinschaft and the Fonds der Chemischen Industrie for generous financial support.

Supporting Information Available: Cyclic voltammogram of 2. Tables of atomic coordinates, isotropic and anisotropic displacement parameters, and all bond lengths and angles. This material is available free of charge via the Internet at http://pubs.acs.org. Further details of the crystal structure determinations are available from the Cambridge Crystall ographic Data Center on quoting the depository number CCDC-135240.

OM990875Q 